\section{Annual General Meeting: Education \& Training Project Committee Report}

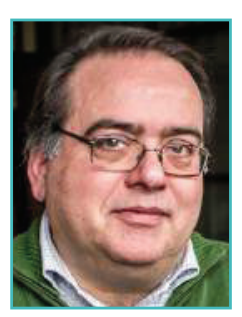

\section{Pedro L Fernandes}

Instituto Gulbenkian de Ciência, Oeiras, Portugal

Received 1 August 2013; Published 19 August 2013

At the end of the 2010-2013 triennium, the Education \& Training Project Committee (E\&T PC) reports its progress as follows:

\section{Revamping the plans}

Our on-going plans were frozen, owing to lack of proper funding. Instead, we started new activities:

- in conjunction with the creation of GOBLET, parallel plans have been prepared to introduce a recognition system for training. Contacts were made with community members, particularly training instructors, to understand their position towards adopting a badges system, a proposal that was uniformly well accepted. The next step will be to form a small group within EMBnet to take the role of endorsing training partners to issue badges. EMBnet can also play a significant role in displaying badges. The Mozilla Open Badges system' became fully functional in recent months. A good example can be found at the cloudworks ${ }^{2}$ website

- a careful look into MOOCs (Massively Open Online Courses) was started, in order to consider the possibility of partnering with educational resources looking for compatible teaching methods. This is the consequence of adopting peer instruction (Eric Mazur) and Flipped-Classes (Aaron Sams and Jonathan Bergman) in formal education. These meth-

1 http://www.openbadges.org

2 http://cloudworks.ac.uk/badge/badge list ods are much better exercised in the training world, and some EMBnet members can provide knowledge in this area;

- the design of interactive courseware to enable proper e-learning is currently under consideration. This requires familiarisation with techniques first, and then with software that allows such tools to be built. We have started talks with software vendors in order to enable EMBnet to have access to development tools for free, or for a very modest price. So far, we have mainly expressions of interest. Some software vendors are considering an extension of existing deals to larger audiences (e.g., Biomatters);'we also participated in talks with industrial parties that can cooperate in bringing their technological expertise to training events, as additional demonstration sessions: e.g., pilot experiments have been successful with Genomatix. This is a growing interest that may lead to mutually beneficial exchanges.

\section{Seeking funding}

Implementation of the activities depicted in the 2010-2013 business plan should be assessed fairly, considering the difficulties in proceeding without funds. As funding is crucial to any of the plans we laid-out, the E\&T PC explored contacts with European project coordinating bodies and expressed its interest in joining EU-funded initiatives, mainly:

- the Grundtvig programme ${ }^{3}$, which focuses on the teaching and study needs of learners taking adult education and 'alternative' education courses, as well as the organisations delivering these services. It aims both to help develop the adult education sector, and to enable more people to undertake learning experiences, especially in other European countries;

- the Leonardo da Vinci Programme ${ }^{4}$, which funds many different activities of varying scales. These include 'mobility' initiatives, enabling people to train in another country, co-operation projects to transfer or develop innovative practices, and networks focusing on topical themes in the sector. Entering these programmes is fundamentally different from

3 http://ec.europa.eu/education/lifelong-learning-programme/grundtvig en.htm

4 http://ec.europa.eu/education/leonardo-da-vinci/initial en.htm 
applying for a research project. It requires contacting their National Agencies and getting 'invited' to attend their workshops with some regularity. Many of these federated structures run local workshops, termed Lifelong Learning Programmes (LLP), which are often out of our scope - e.g., those on Learning Languages (idioms) or Occupational Geriatrics. However, we must be attentive to areas that are lateral to their actions, such as those on Medical Education, in which we aim at a small share for bioinformatics.

We have found that while these sources have to be considered and negotiations should not stop, funds are pre-allocated to activities, making it difficult to propose new ones.

It is generally felt that EMBnet is in need of a more encompassing funding plan in which the E\&T PC can provide cost estimates, data and texts to write grant applications that have an E\&T component.

\section{Outreach}

EMBnet's track record in training provision throughout its constituency was presented in a talk about networking in science, in which EMBnet's roles were described, at the ABRF conference ${ }^{5}$ in Orlando, FL, March 2012. The talk generated a series of contacts that may result in institutional exchanges that lead to training cooperation worldwide, in places where EMBnet's activity is poorly known.

As genomics reaches the clinical arena, it is increasingly evident that the public are largely unprepared for the implications of using personal genome data, in terms of consent. This issue could be less problematic if the educational system helped create a common, informed awareness. In collaboration with Pietro Liò and Lucia Bianchi, such a proposal was made in a paper accepted for The future of Education ${ }^{6}$ conference in Florence (June 2013) entitled, "Improving collective awareness and education about the privacy and ethical issues connected with the genome technologies".

Furthermore, the prospect of using EMBnet's global presence in educational initiatives has been mentioned in talks in Portuguese academic institutions (e.g., Braga, March 2013 and Porto, May 2013) triggering interesting discussions on the need to use networked communities in globalised educational efforts, like MOOCs.

\section{Committee members}

Pedro Fernandes (PT) Chair

Emiliano Barreto (CO) Secretary

Bruno A. Gaeta (AUS) Member

Shahid Chohan (PK) Member

\section{Associate members}

J.R Valverde (ES)

Mohamed Abelhouda (EG)

Matej Stano (SK)

5 http://www.abrf.org/index.cfm/page/meetings/ABRF2012/ ABRF2012 